\title{
REVIEW
}

\section{Effects of biological and non-biological immunomodulatory therapies on the immunogenicity of vaccines in patients with rheumatic diseases}

\author{
Zsuzsanna H McMahan * and Clifton O Bingham III
}

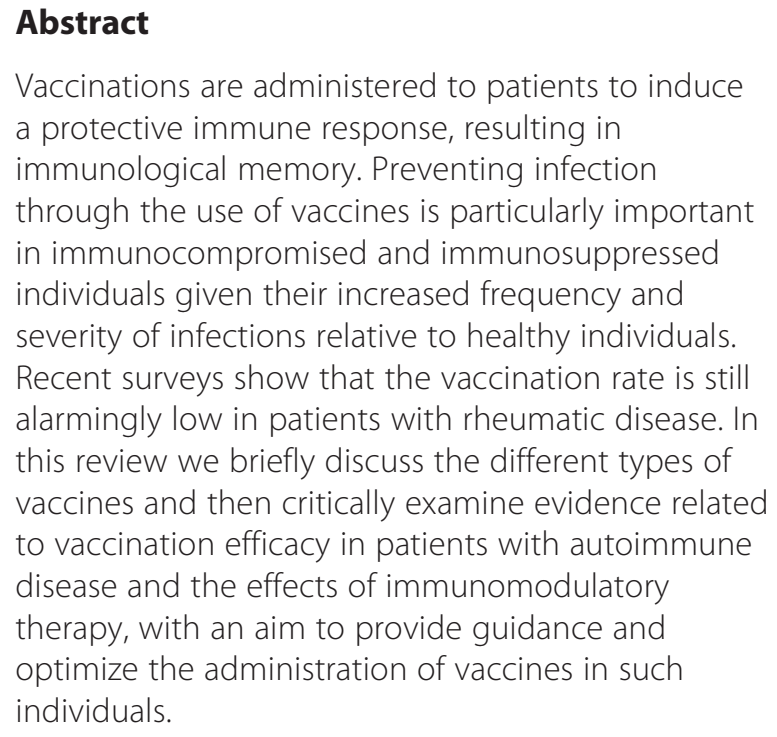

\section{Introduction}

Immunizations are effective in inducing and/or enhancing protective immunity, and may be particularly important in the immunocompromised. Autoimmunity often imparts an increased risk for infection with additional medication-related risks, and common infections have higher morbidity and mortality. Optimizing care for patients with autoimmune disease requires treatment of the underlying disease and minimizing infectionrelated comorbidity, with vaccination as an important component.

\footnotetext{
* Correspondence: zmcmaha1@jhmi.edu

Department of Medicine, Division of Rheumatology, Johns Hopkins University, 5200 Eastern Avenue, Mason F Lord Center Tower, Room 4100, Baltimore, MD 21224, USA
}

Treatments for rheumatic diseases have greatly expanded in the last 15 years, encompassing biological and nonbiological pathway inhibitors, all associated with infections, and with consequent interest in mitigating this risk. Patients taking immunomodulators have suboptimal rates of immunizations, due in part to concerns over vaccine-associated adverse events, possible activation of the underlying autoimmune process, and questions of vaccine efficacy [1,2]. New guidelines and recommendations provide conflicting information and/or inadequately address specific rheumatologic concerns. Proportions of heumatologic patients vaccinated for influenza are $40 \%$ less, and in US Medicare recipients, only 33\% of rheuatoid arthritis (RA) and psoriatic arthritis patients rea pneumococcal vaccine over a 5 year period [1]

Our goals are to critically examine evidence regarding immunization efficacy in autoimmune diseases and with the array of immunomodulatory agents used in the management of these patients. This review will provide data to inform decisions to optimize vaccine efficacy, avoid

\section{Methods}

e conducted this review to evaluate immunization efficacy in rheumatic conditions and with different immunoulators, including both biological and non-biologica listed in Table 1. Relevant abstract were included as well as guidelines and recommendations from immunological, infectious diseases, and rheumatologic societies, and the Centers for Disease Control (CDC), and descriptions of studies and results from ClinicalTrials.gov. Additional articles were obtained from reference lists and authors' personal collections. An initial 


\section{Table 1 Search terms}

\begin{abstract}
Search terms
immunization, vaccines, vaccination, systemic lupus erythematosus, vasculitis, rheumatoid arthritis, limited and diffuse scleroderma, systemic sclerosis, myositis, juvenile rheumatoid arthritis, discoid lupus erythematosus, autoimmune diseases, transplants, pediatric, hydroxycorticosteroids, glucocorticoids, cyclosporine, sirolimus, tacrolimus, mycophenolate mofetil, azathioprine, 6-mercaptopurine, methotrexate, hydroxychloroquine, sulfasalazine, leflunomide, TNFR-Fc fusion protein, etanercept, abatacept, rituximab, tocilizumab, infliximab, adalimumab, CDP870, certolizumab, and golimumab, limited to articles after 1980
\end{abstract}

search resulted in 7,226 articles, which were screened and selected for clinical studies and reviews evaluating responses to vaccines in patients with autoimmune diseases and transplants receiving immunomodulatory therapy. After selection was complete, 147 papers were reviewed in depth. Among studies there was significant heterogeneity; in some studies immune responses were reported for patients receiving different medications, and in some participants were taking multiple agents. We extracted data from these articles by drug if possible for presentation, and have presented summaries for each of the drugs and/ or classes using the most salient examples and references. Given the paucity of published information for many immunomodulatory therapies currently being used, we have also included abstract data from ACR and EULAR meetings to provide clinicians with additional data to inform clinical decision-making.

\section{Immunizations: general overview}

Vaccines vary in their components, including recombinant or purified protein antigens, live attenuated or killed organisms, carbohydrate and polysaccharide antigens, and conjugates (Table 2). Each mechanism activates different immunological pathways with efficacy and safety implications and may invoke a neoantigen or booster response.

Live organism vaccines, typically viruses with attenuated virulence but also live bacteria, generally induce high titer and long-lasting immune responses (Table 3). Most are viruses (for example, zoster, varicella, yellow fever, measles/ mumps/rubella (MMR), intranasal influenza, oral polio, and rotavirus) but some are live bacteria (for example, oral typhoid, Bacillus Calmette-Guérin). Their recognition is of paramount importance for immunosuppressed patients because they may induce illness even from an attenuated strain [3]; thus, live vaccines are not recommended for patients on many disease-modifying anti-rheumatic drugs (DMARDs) and immunomodulators.

There is a paucity of data available, but the CDC has provided recommendations for the immunosuppressed with some vaccines and particular drugs; however, categorization of immunosuppression is quite broad and includes congenital immunodeficiencies, HIV infection, chemotherapy-induced marrow ablation, transplant-related immunosuppression, and rheumatic disease patients receiving immunomodulators. The attenuated live varicella zoster vaccine is recommended for adults aged over 60 years, regardless of prior chicken pox infection, immunization, serology, or shingles history and may be used in patients aged 50 to 59 years with potentially poor tolerance to zoster infection or post-herpetic neuralgia. CDC guidance has been published for zoster vaccine use in the immunosuppressed [4]. The vaccine may be given to patients with decreased humoral immunity (that is, isolated immunoglobulin (Ig) deficiency), patients receiving low to moderate dose steroids ( $<20 \mathrm{mg} /$ day prednisone), and patients on $>20 \mathrm{mg}$ prednisone for $\geq 2$ weeks after 1 month of discontinuation. The zoster vaccine can be used with doses of methotrexate (MTX), azathioprine (AZA), and 6-mercaptopurine typically used in autoimmune disease treatment.

Concerns remain regarding live vaccine safety with other biological therapies and immunosuppressants. Although recent reports using managed care and Medicare/ Medicaid databases suggest that patients receiving tumor necrosis factor (TNF) inhibitors may be able to receive the zoster vaccine without adverse effect $[5,6]$, further prospective studies are needed. In juvenile rheumatic disease patients on MTX and corticosteroids the live varicella vaccine did not cause any overt infections [7]. While there is a concern for potential conversion to a virulent form of varicella in the immunocompromised, effective antiviral drugs such as acyclovir and valacyclovir are available to treat acute infections should they arise. In patients receiving the zoster vaccine, these antivirals should be discontinued before immunization and several weeks thereafter to maximize response. MMR vaccines have also been administered to children with pediatric rheumatic diseases receiving immunodulators. In one study, there were no cases of viral activation or illness with MMR in children with juvenile idiopathic arthritis (JIA) taking MTX or etanercept [8]. An important caveat for zoster and MMR vaccine studies is that these largely represented recall or booster responses of preexisting immunological memory, which may have attenuated the risk of virulent conversion. The yellow fever vaccine is also a live virus and required for travel to many regions in the world, thus representing a neoantigen for most. Although the live yellow fever vaccine was given without sequelae to 17 Brazilian RA patients receiving infliximab, this was as part of a reimmunization effort rather than a neoantigen response; these results cannot be extrapolated to immunocompromised individuals receiving yellow fever vaccine for the first time [9]. There are limited data concerning the risk to immunosuppressed individuals of acquiring infection from a family member or close contact who receives a live virus vaccine [10]. In studies of live attenuated intranasal influenza vaccine administration in pediatric cancer [11], 
Table 2 Types of vaccines and examples

\begin{tabular}{|c|c|c|}
\hline Carbohydrate/polysaccharide antigens & $\begin{array}{l}\text { Protein antigen: recombinant/inactivated/ } \\
\text { conjugated** }\end{array}$ & Live/attenuated organisms \\
\hline $\begin{array}{l}\text { Pneumococcal polysaccharide (PPSV-23, } \\
\text { for example, Pneumovax }{ }^{\oplus} \text { ) }\end{array}$ & $\begin{array}{l}\text { Tetanus, diphtheria, acellular pertussis (TD/DT, TDAP, } \\
\text { DTAP) }\end{array}$ & Varicella (VZV, Varivax ${ }^{\oplus}$, Varilrix $\left.{ }^{\oplus}\right)$ \\
\hline Meningococcal polysaccharide (MPSV-4) & Hepatitis A, hepatitis B & Shingles, zoster (for example, Zostavax ${ }^{\circledR}$ ) \\
\hline \multirow[t]{11}{*}{ Typhoid polysaccharide (Vi injection) } & Seasonal influenza A/B injection & Intranasal influenza (for example, Flu-mist ${ }^{\oplus}$ ) \\
\hline & Pandemic influenza (H1N1) injection & \\
\hline & Human papilloma virus & Measles, mumps, rubella \\
\hline & Anthrax (acellular) & Yellow fever \\
\hline & Inactivated polio (IPV, Salk, IM/SQ) & Oral polio (OPV) \\
\hline & Oral cholera (killed cells) & Typhoid (Ty21a oral) \\
\hline & $\begin{array}{l}\text { Pneumococcal conjugate }{ }^{* *} \text { (PCV-7, PCV-13, for } \\
\left.\text { example, Prevnar }{ }^{\oplus}\right)\end{array}$ & Vaccinia (smallpox) \\
\hline & Meningococcal conjugate ${ }^{* *}(\mathrm{MCV}-4,<55$ years old $)$ & Bacillus Calmette-Guérin \\
\hline & \multirow{3}{*}{$\begin{array}{l}\text { Haemophilus influenza type B protein } \\
\text { polysaccharide conjugate }{ }^{* *}(\mathrm{HiB}, \mathrm{PRP})\end{array}$} & Rotavirus \\
\hline & & Anthrax (live spore) \\
\hline & & Smallpox \\
\hline
\end{tabular}

Vaccinations may vary in terms of their constituents from country to country (for example, Japanese encephalitis virus, rabies, anthrax) and over time as new vaccines are developed. Providers are advised to consult product inserts of specific vaccines to confirm constituents before use. DTAP, diphtheria, tetanus, and pertussis; HiB, Haemophilus influenza type B; IM/SQ, intramuscular/subcutaneous; IPV, inactivated polio virus; MCV-4, quadrivalent meningococcal conjugate; MPSV-4, quadravalent meningococcal polysaccharide vaccine; OPV, oral polio virus; PCV, pneumococcal conjugate vaccine; PPSV, pneumococcal polysaccharide vaccine; PRP, polyribosylribitol phosphate; TD/DT, Tetanus Diphtheria/Diphtheria Tetanus; TDAP, Tetanus diphtheria acellular pertussis; Vi, Vi capsular polysaccharide; VZV, varicella zoster vaccine. ${ }^{* *}$ conjugated vaccines.

viral shedding was limited to $<7$ to 10 days, but the vaccine is not recommended by the CDC in the immunocompromised or adults aged over 50 years [12]. Household contacts of immunosuppressed patients without immunity may also receive live virus vaccines, as transmission of attenuated vaccine strain virus is rare, but caution should still be exercised. Recently published recommendations concerning viral transmission risk to patients with immunodeficiencies from family contacts receiving vaccines noted that these events were possible but rare [10].

Recombinant protein antigen vaccines and killed virus vaccines are also used but may have decreased immunogenicity (relative to live vaccines) and require multiple doses. Polysaccharide or carbohydrate antigen vaccines were developed for some encapsulated organisms, including pneumococcus (23-valent pneumococcal polysaccharide vaccine (PPSV-23), Pneumovax ${ }^{\circ}$ ), and meningococcus (quadravalent meningococcal polysaccharide vaccine-4). Polysaccharide immunization responses largely reflect T-cell-independent mechanisms. Protein-conjugate vaccines, such as 7- and 13-valent pneumococcal conjugate (PCV-7, PCV-13 or Prevnar ${ }^{\circ}$ ), meningococcal conjugate (MCV-4), and conjugated Haemophilus influenza type B (HiB) attach polysaccharide antigens to a carrier protein to enhance response. The CDC Advisory Committee on Immunization Practices now recommends PCV-13 to all immunocompromised adults aged over 19 years, followed $\geq 8$ weeks later by PPSV-23 to induce optimal memory, with subsequent PPSV-23 every 5 years $[12,13]$. In patients who received prior PPSV-23, at least 1 year is recommended before giving PCV-13.

\section{Measuring vaccine responses}

One difficulty in evaluating various vaccine studies is a lack of standardized reporting. Although vaccines elicit cellular and humoral immunity, efficacy is primarily measured by antibody titers. Four general parameters are used to measure vaccine response: 1 ) geometric mean titers (GMTs), 2) seroprotection rate, 3) seroconversion rate, and 4) seroconversion factor. A four-fold rise in GMT is one measure of vaccine efficacy, though some studies report two-fold increases. The seroprotection rate represents the percentage of recipients with an antibody titer at which the probability of protection is assumed to be $50 \%$, but protective levels are poorly standardized and may vary among studies and between vaccines, and indeed between individuals. Seroconversion rates describe the percentage of recipients with a two- to four-fold or more increase in post-vaccination titers. The seroconversion factor is defined as the post-vaccination titer divided by the pre-vaccination titer. Some studies have shown adequate seroprotection but without expected increases in antibody titers, attributed to cellular immunity. Other studies have only reported increases in titers for patients without baseline levels of protective titers (rather than all patients receiving the vaccine), leading to difficulties in comparing study results. For the majority of vaccines, the 
Table 3 Summary of data for vaccine efficacy and safety with immunomodulatory therapies

\begin{tabular}{|c|c|c|c|c|c|}
\hline Drug & $\begin{array}{l}\text { Protein } \\
\text { vaccines }\end{array}$ & $\begin{array}{l}\text { Carbohydrate } \\
\text { vaccines }\end{array}$ & $\begin{array}{l}\text { DTH/cellular } \\
\text { immunity }\end{array}$ & Neoantigen & Live virus \\
\hline \multicolumn{6}{|l|}{ Non-biologic immunomodulators } \\
\hline Corticosteroids & $--/ \downarrow$ & -- & ND & ND & Zoster OK with CCS <20 mg/day \\
\hline Methotrexate & $\downarrow \downarrow$ & $\downarrow$ & -- & -- & Zoster OK with MTX <0.4 mg/kg/week \\
\hline Anti-malarials & -- & -- & ND & ND & Probably safe, possible $\downarrow$ response \\
\hline Sulfasalazine & $--/ \downarrow$ & ND & ND & ND & Probably safe, not formally studied \\
\hline Leflunomide & -- & ND & ND & ND & ND \\
\hline Azathioprine & -- & $--/ \downarrow$ & ND & ND & Zoster OK <3 mg/kg/day \\
\hline Mycophenolate & $\downarrow \downarrow$ & $\downarrow \downarrow$ & $\downarrow$ & $\downarrow$ & Avoid \\
\hline Calcineurin Inhibitors & $--/ \downarrow$ & ND & $\downarrow$ & ND & Avoid \\
\hline \multicolumn{6}{|l|}{ Biologicals and targeted immunomodulators } \\
\hline TNF inhibitors & $--/ \downarrow$ & $--/ \downarrow$ & -- & ND & Avoid \\
\hline Abatacept (CTLA4-Ig) & $\downarrow$ & $\downarrow$ & ND & $\downarrow$ & Avoid \\
\hline Rituximab (anti-CD20) & $--/ \downarrow$ & $\downarrow \downarrow$ & $\downarrow$ & $\downarrow \downarrow$ & Avoid \\
\hline Tocilizumab (anti-IL6) & -- & -- & ND & ND & Avoid \\
\hline Ustekinumab (anti-IL-12/23) & -- & -- & ND & ND & Avoid \\
\hline IL-1 inhibitors (anakinra, Rilonacept, canakinumab) & ND & ND & ND & ND & Avoid \\
\hline Belimumab (anti-BLyS) & ND & ND & ND & ND & Avoid \\
\hline Tofacitinib (Jak1/3) & $--/ \downarrow$ & $\downarrow$ & ND & ND & Avoid \\
\hline
\end{tabular}

$\downarrow$ decreased, $\downarrow \downarrow$ markedly decreased, -- no effect. BLyS, B lymphocyte stimulator; CCS, corticosteroids; DTH, delayed type hypersensitivity; MTX, methotrexate; ND, not determined; TNF, tumor necrosis factor.

protective correlates, especially cellular immune correlates and nasal and/or serum IgA, are poorly defined. Hence, in a majority of cases, only serum antibody-mediated assessments serve as correlates due to the complexity of assessment of cell-mediated immune responses.

Antibody responses reported as endpoints in most studies reflect a defined point in time (typically 4 weeks after immunization), but do not necessarily reflect titer maintenance. Although mounting an early response is assumed to result in development of immunological memory, few studies have evaluated titer durability over time or the efficacy of boosting in immunocompromised patients. Strategies to increase vaccine responses include addition of adjuvant, booster vaccinations, increasing antigen dose, and intradermal administration.

\section{Results}

Rheumatic diseases are managed with a variety of immunomodulators, ranging from corticosteroids to non-biological and biologic DMARDS and immunosuppressives (Figure 1).

\section{Non-biological agents \\ Corticosteroids}

Immune responses of autoimmune disease patients taking steroids have been well studied [14]. Even at low doses overall infection and opportunistic infections are increased $[15,16]$. Studies evaluated systemic lupus erythematosus (SLE), JIA, polyangiitis with granulomatosis, scleroderma, RA, and renal transplants, with influenza, tetanus, PPSV-23, HiB, and hepatitis B virus (HBV) vaccines. In most, glucocorticoids impaired vaccine response, and decreased cellular responses to diphtheria and tetanus were reported in transplant patients receiving steroids.

\section{Methotrexate}

Many studies evaluated responses to vaccines with MTX, most in RA, but also JIA, psoriatic arthritis, and SLE [8,14,17-19]. Vaccines included PPSV-23, PCV-7, $\mathrm{HBV}$, influenza, MMR, the neoantigen keyhole limpet hemocyanin $(\mathrm{KLH})$, and delayed type hypersensitivity (DTH) reactions. In 17 RA patients on MTX (mean dose $11.6 \mathrm{mg} /$ week) responses to recombinant $\mathrm{HBV}$ protein vaccine were seen in 68\%, and use of MTX was not associated with lack of response [14]. In two studies, RA patients on MTX responded similarly to healthy controls for influenza [19], with GMTs significantly increased against each strain; however, the percentage of responders was lower in RA. Pneumococcal responses were also evaluated with MTX, using PPSV-23 or PCV-7 [20]. In a direct comparison, responses to PPSV-23 were similar to those to PCV-7; but MTX has emerged as a predictor of poor response, with a greater effect than TNF inhibitors [20,21]. 


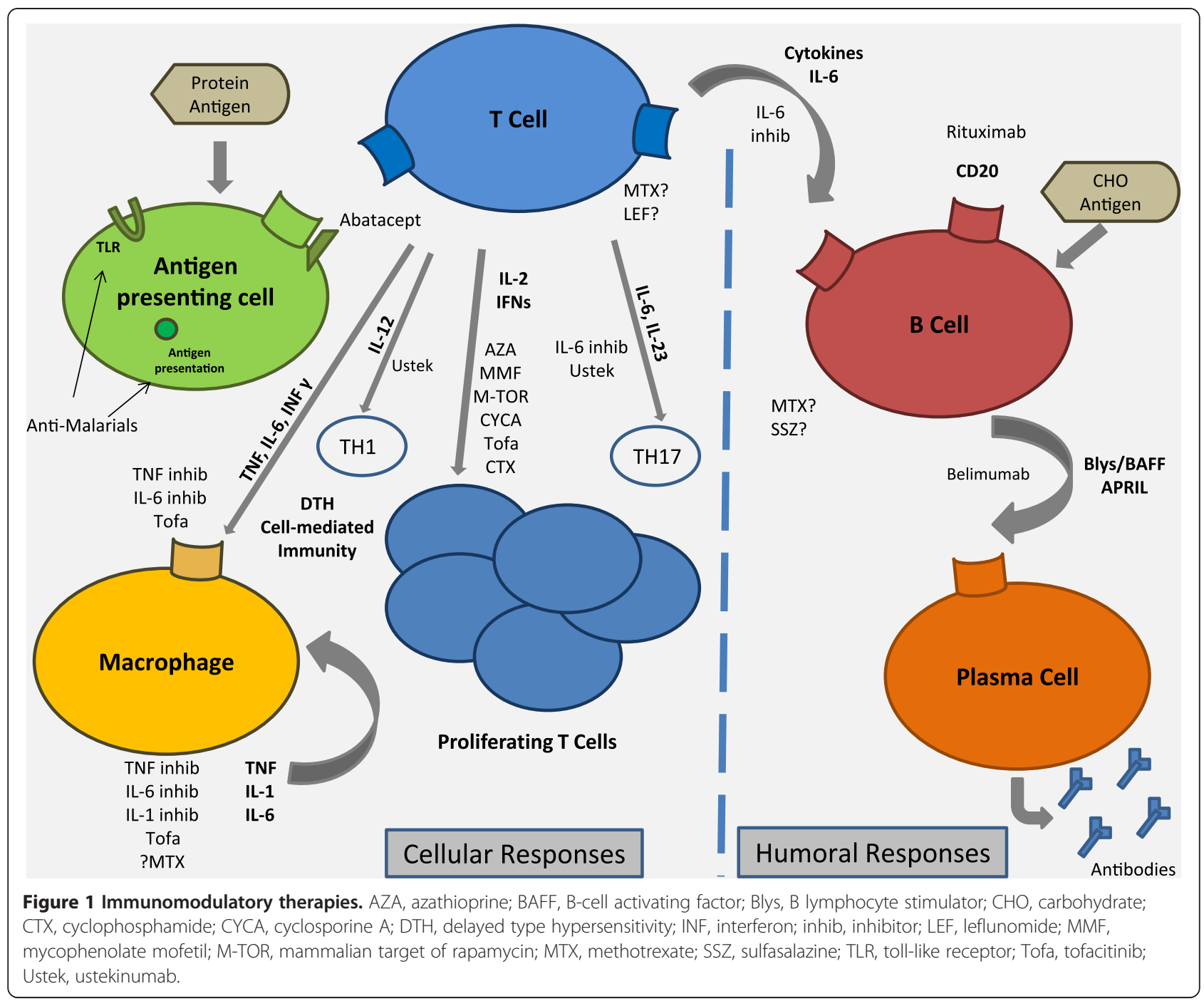

Bingham and colleagues reported immune responses in 20 RA patients on MTX monotherapy to tetanus toxoid (TT), PPSV-23, KLH, and DTH. TT responses were seen in only $42.3 \%$ on MTX, lower than that expected for 'normal' controls (>70 to 80\%) [18]. Responses to PPSV-23 ranged from $29 \%$ to $61 \%$ for individual serotypes, but $79 \%$ responded to $\geq 3$ serotypes. Ninety-three percent treated with MTX had detectable anti-KLH IgG neoantigen responses, and most (70\%) maintained positive DTH response. In a more recent study, 23 RA patients on MTX monotherapy had similar reductions in TT $(39 \%$ responders) and PPSV-23 responses (70.8\% with 6 serotypes) [22].

In 10 JIA patients on MTX who received MMR booster vaccinations, those treated with MTX alone had reduced humoral responses, and while there was no reduction in titer with MTX plus TNF inhibitors, markers of cell-mediated immunity were reduced [8]. Seroprotection rates and GMT for mumps, rubella, diphtheria, and tetanus were recently reported to be lower in JIA than controls, but unrelated to MTX exposure [23].

In summary, MTX may reduce response in patients receiving some protein antigens (influenza and TT) but retention of others (for example, KLH). Reductions in polysaccharide and conjugated pneumococcal responses are reported, but most individuals mount responses to multiple serotypes. The safety of live virus booster vaccines was demonstrated for MMR with MTX, and zoster vaccines may also be administered to these patients.

\section{Other non-biological DMARDs}

Immunization efficacy was studied with chloroquine and hydroxychloroquine (HCQ) in SLE and RA, and healthy individuals for malaria prophylaxis [24]. Responses to yellow fever, oral polio, oral cholera and typhoid vaccines, PPSV-23, human papilloma virus (HPV), and influenza vaccines were analyzed. Little or no impairment in responses were reported with anti-malarials [25]. 
Importantly, no illness or activation of live attenuated yellow fever vaccine occurred. One study evaluated immunogenicity and safety of HPV vaccine in 50 women with SLE and 50 healthy controls; among the $66 \%$ of SLE patients on $\mathrm{HCQ}$, there was no significant reduction in seroconversion rates [26].

Immunization efficacy with sulfasalazine (SSZ) has also been studied $[27,28]$. In one study, responses to TT or inactivated influenza were evaluated in 23 healthy subjects receiving SSZ or placebo, demonstrating a significant reduction in IgG and IgA anti-tetanus-producing cells [27]. In a contrasting study, SSZ had no effect on immunization responses to adjuvented pandemic influenza vaccine [25]. In seven JIA patients on SSZ only one was a low responder,' to MCV-4 [29].

Vaccination responses with leflunomide have not been well-studied. Ribeiro and colleagues [30] evaluated immune responses to the trivalent influenza vaccine in RA. Among 340 patients on combinations of DMARDs (42.9\% on leflunomide) compared with 230 healthy controls, leflunomide use was not associated with decreased immune response.

\section{Azathioprine}

A considerable amount of data is available for AZA in patients with SLE, inflammatory arthritis, polyangiitis with granulomatosis, and renal transplant using different vaccines (influenza, injectable typhoid, PPSV, TT, and $\mathrm{HiB}$ ) [31-33]. Studies of influenza responses are conflicting between reports, with some showing no reductions in responses [32] and others demonstrating decreased seroconversion, reduction in GMTs, and fewer four-fold titer increases with AZA [31,32]. Responses to other vaccines, including TT, PPSV-23, HBV, and the HPV vaccine were not, however, significantly decreased with AZA. Across these studies variable endpoints were used to define a response [26].

\section{Mycophenolate}

Influenza vaccine responses, seroprotection rates, and seroconversion rates were reduced with mycophenolate (MMF) compared with AZA in transplant recipients [34]. In another transplant study that evaluated cellular, humoral, and recall responses to PPSV and TT vaccines, patients on MMF were unable to mount a primary humoral or recall response to TT and PPSV-23, and cellular responses to TT were also reduced [35]. With the HPV vaccine in SLE, those on MMF had reduced seroconversion rates for two genotypes compared with patients receiving other immunodulators (HCQ, AZA, and calcineurin inhibitors), and titers were inversely correlated with MMF dose [26]. There are limited data on the more potent immunosuppressant, cyclophosphamide, in rheumatic diseases. The response to PPSV-23 in two patients with systemic sclerosis on cyclophosphamide was severely impaired [36].

\section{Cyclosporine and calcineurin inhibitors}

The effects of cyclosporine (CycA) on immune responses have been studied in transplant recipients with influenza, KLH, TT, and HBV [37,38]. In these studies, controls were typically patients receiving other immunomodulators (for example, AZA, MMF, sirolimus), and usually steroids [35,39]. In one study, CycA-treated patients had a lower immune response against influenza $A$ than AZA-treated patients, and boosters were not effective. Another group reported significantly decreased responses to influenza with CycA compared with sirolimus in lung transplants. In CycA-treated chronic uveitis patients, significantly decreased DTH was seen, but without differences in responses to KLH or TT [37].

\section{Biologics}

\section{Tumor necrosis factor inhibitors}

Several studies, mostly in RA, have evaluated immunizations with TNF inhibitors [17,21,39-42]. Influenza and pneumococcal responses were the focus of most, but MMR was studied in JIA. Overall, vaccination with TNF monotherapy was effective, but a combination of MTX with TNF inhibitors showed significantly decreased responses [20,21]. In two JIA studies with the conjugate pneumococcal vaccine (PCV-7) or MMR re-vaccination, MTX and etanercept did not decrease responses. One small study demonstrated that there was no reduction in DTH responses with etanercept [43]. Although live virus vaccines are not recommended in patients receiving biologics, the incidence of herpes zoster in patients receiving TNF inhibitors was not increased compared with non-biological DMARDs [6]. Although a small study reported that booster live attenuated yellow fever vaccines did not cause illness, these were recall responses and not first exposure to the vaccine [9]. Overall, the available data would support that vaccination with non-live viruses in patients receiving TNF inhibitors may have slight reductions in response, but these are likely protective. While some data suggest that certain live virus vaccines eliciting booster or recall responses may be safe in patients receiving TNF inhibitors (for example, zoster, MMR), extrapolation to live organism neoantigen immunizations cannot be assumed, and additional studies are necessary.

\section{Abatacept}

Immunization responses with abatacept, which blocks T-cell activation via co-stimulatory pathways, were studied in RA, psoriasis, and healthy controls. In healthy individuals, abatacept did not inhibit responses to TT or PPSV-23 [44]. Patients with RA on abatacept vaccinated 
with the conjugated PCV-7 had a diminished response [45], with only $48 \%$ mounting a response to $\geq 3$ serotypes. Psoriasis patients on abatacept showed decreased responses to both the bacteriophage PhiX and KLH neoantigens [46]. A recent open-label study reported the efficacy of PPSV-23 and seasonal influenza vaccines in RA patients taking subcutaneous abatacept plus background DMARDS. In those without protective titers at baseline, 73.9\% mounted a response to PPSV-23 (defined as a two-fold increase in three out of five antigens), with $83.9 \%$ developing protective titers. Only $61.3 \%$ had a response to influenza vaccine (four-fold increase in two out of three antigens), but $82.1 \%$ had protective titers [47].

\section{Rituximab}

By inhibiting B cells, rituximab (RTX) may affect humoral immunity as evidenced by total IgM and IgG slowly declining with repeated administration. In rheumatic disease patients, a number of studies have evaluated vaccine responses with RTX with influenza TT, PPSV-23, DTH, and KLH, mostly in RA $[19,48]$. In a large study of RA patients on RTX and MTX, immunizations were given after a first course of RTX during the period of B-cell depletion. Responses to TT and DTH were preserved at 24 weeks compared with MTX alone, but neoantigen responses (KLH) and responses to PPSV-23 were significantly reduced [18]. In other RA studies, patients on RTX had significantly diminished responses to influenza vaccine, with one group showing better responses as a booster response than as a neoantigen $[19,48]$. Although humoral responses were reduced, T-cell responses to vaccine antigens were similar with RTX compared with other DMARDs [49]. Because patients treated with RTX may have potentially fatal reactivation of latent viral infections, live virus vaccines should be strictly avoided. Current vaccine studies of RTX are limited to treatment with a single course of therapy. Whether responses would be impaired further with subsequent courses requires additional study.

\section{Belimumab}

A recent study reported responses to PPSV-23, influenza, and TT vaccines in SLE patients receiving belimumab directed against the cytokine B lymphocyte stimulator involved in plasma cell differentiation [50]. Belimumab had no significant effect on the maintenance of antibody titers in previously vaccinated patients, but there were no controls, and vaccine exposure was not standardized.

\section{Tocilizumab}

Interleukin (IL)-6 has pleiotropic activity, including effects on B-cell and T-cell differentiation and development. In a small open-label study protective antibody titers to influenza were reached in over $70 \%$ of tocilizumab (TCZ)-treated RA patients [51]. A controlled study (TCZ plus MTX versus MTX) was conducted in RA patients who received TCZ ( $8 \mathrm{mg} / \mathrm{kg})$, with TT and PPSV-23 given after 3 weeks and responses measured at 8 weeks after one additional TCZ infusion. Numerically more patients responded to PPSV-23 based on a twofold increase in titer in $\geq 6$ serotypes with MTX versus TCZ plus MTX (70.8\% versus 60\%), but confidence intervals were overlapping. Responses to TT were seen in only 39\% of patients receiving MTX alone, but not further attenuated with TCZ plus MTX (42\%) [52]. A limitation of this study was exposure to only two TCZ infusions at the time of immunization. To date, no information is available using other IL-6 inhibitors in development.

\section{Ustekinumab}

There has been increasing appreciation of the role of the IL-12/23 and IL-17 pathways in several rheumatic diseases. Ustekinumab (UST), which binds and inhibits signaling by both IL-12 and IL-23, has been approved for the treatment of psoriatic arthritis. Responses to TT and PPSV-23 were examined in patients with psoriasis receiving prolonged treatment with UST $(n=60)$ and compared with a control group of psoriasis patients not taking systemic therapy $(n=56)$. There was no demonstrable impairment in responses to PPSV-23; $>2$-fold increases were seen for $\geq 7$ of 14 pneumococcal serotypes in $96.6 \%$ of UST-treated patients and $92.6 \%$ of controls. Similarly, there was no decrement in responses to TT ( $\geq 4$-fold increase) in patients following vaccination, with $84.7 \%$ of UST-treated and $77.8 \%$ of controls having responses. Cellular responses to TT were also examined and showed no difference between groups [53].

\section{Interleukin-1 inhibitors}

There is limited information on immunization responses in patients receiving anakinra, an IL-1 receptor antagonist approved for RA, the IL-1R-Accessory Protein fusion protein rilonacept, or the anti-IL1- $\beta$ antibody canakinumab. The effects of anakinra on vaccine antibody responses in patients with RA were studied, but these results have never been presented.

\section{Tofacitinib}

The most recently approved agent in the US for the treatment of RA is the Janus kinase (Jak) inhibitor tofacitinib, which preferentially blocks Jaks 1 and 3, with additional Jak inhibitors in development. While not 'biologic' in terms of its molecular structure, it inhibits downstream activities of multiple cytokine and growth factors, including IL-6 and the T-cell cytokines IL-2 and interferons. To date, only abstract data have been presented concerning 
immunization efficacy with tofacitinib. In the first study, PPSV-23 and influenza vaccines were administered to patients taking long-term tofacitinib, some stopping tofacitinib 2 weeks before immunization and others without tofacitinib interruption. There was no significant difference in response to PPSV-23 (>2-fold increase in 6 of 12 antigens; $75 \%$ versus $84.6 \%$ ) or influenza ( $>4$-fold increase in 2 of 3 antigens; $66.3 \%$ versus $61.8 \%$ ) between continuous exposure and 2-week tofacitinib withdrawal, but titers were higher in those taken off tofacitinib before immunization [54]. A larger study was conducted in RA patients on $10 \mathrm{mg}$ bid of tofacitinib alone or placebo stratified for MTX use using influenza and PPSV-23 vaccines, with response measured at 35 days. Similar proportions of patients had responses to influenza ( $\geq 4$-fold increase in 2 of 3 antigens) in tofacitinib versus placebo (56.9\% versus $62.2 \%$ ) with some reductions seen in those on MTX. With PPSV-23, only $45.1 \%$ of those on tofacitinib had a response ( $\geq 2$-fold increase in 6 of 12 antigens) compared with $68.4 \%$ on placebo, with the differences most notable in those on MTX versus no MTX as cotherapy $[54,55]$. As with other immunomodulators, live virus vaccines in patients treated with tofacitinib should be avoided.

\section{Conclusion}

Immunizations remain an important component of risk mitigation for patients receiving immunomodulatory therapies, but there are important caveats to consider for individual patients and with specific drugs in terms of efficacy and potentially with safety. Vaccines remain immunogenic, although responses may be somewhat attenuated with certain drugs. The magnitude of the immune response to vaccines in RA depends on 1) preexisting memory at the $\mathrm{T}$ - and $\mathrm{B}$-cell level as the antigen and co-stimulatory threshold requirements are lower for memory populations, 2) the nature of the immunosuppressant (B-cell depleting versus others), 3) the timing of vaccination, and 4) whether or not the vaccine is adjuvented. The optimal time for administration to achieve optimal titers and memory is ideally before the initiation of immunomodulators, though this may not always be possible. Most routine vaccinations should be administered according to current guidelines to all patients with rheumatic diseases taking immunosuppressive medications.

Live vaccines should be avoided in patients taking most immunosuppressive and immunomodulatory therapies, ideally administered prior to DMARD initiation. The zoster vaccination may be safe in patients receiving MTX, AZA, or moderately dosed prednisone. While MMR has been administered as a booster to children taking MTX and TNF inhibitors without reported sequelae, this has not been formally studied. There are limited data regarding the safety of other live virus vaccines (for example, intranasal influenza, yellow fever) in rheumatic disease patients taking DMARDs or biologics. While possible, live viral shedding from household members or close contacts to rheumatic disease patients taking immunosuppressive therapies has not been well documented. If live virus vaccines are required in patients on immunosuppressives, there is no evidence base upon which to provide guidance for how long a patient should be off a particular agent before receipt of the vaccine; this would need to factor in both the pharmacokinetics as well as the pharmacodynamics of individual compounds. The potential of utilizing a combination of human monoclonal antibodies against infectious agents may be a focus of future applications and could expand vaccine applications.

Recommendations for vaccination in patients with rheumatic diseases have been published by EULAR and ACR based on available evidence and expert consensus. Since their publication, a number of new drugs have been approved, and additional data have been presented as abstracts and manuscripts for already approved drugs discussed in this paper, and additional vaccine recommendations have been issued regarding immunizations in general and in the immunocompromised. These include recommendations for pertussis inclusion with tetanus boosters in all individuals, given the resurgence of whooping cough and waning immunity in adults and recommendations for the conjugated PCV-13 in immunosuppressed adults followed by PPSV-23.

More controlled studies are needed to evaluate immunization efficacy with existing agents and as part of the evaluation of new drugs. To interpret such data, controls with the disease under study taking an alternative standard regimen (for example, MTX in RA studies) and healthy controls are needed. The current lack of standardized reporting of results from immunization studies makes cross-study comparisons difficult. Additional evaluation of humoral and cellular immune responses following prolonged periods of immunomodulatory use is needed. Finally, studying booster immunizations for suboptimal responders and to maintain titers in those on immunosuppressants, and the optimal timing of vaccine administration are also areas that merit further investigation.

\footnotetext{
Abbreviations

ACR: American College of Rheumatology; AZA: Azathioprine; CDC: Centers for Disease Control; CycA: Cyclosporine; DMARD: Disease-modifying anti-rheumatic drug; DTH: Delayed type hypersensitivity; EULAR: European League Against Rheumatism; GMT: Geometric mean titer; HBV: Hepatitis B virus; HCQ: Hydroxychloroquine; HiB: Haemophilus influenza type B; HPV: Human papilloma virus; Ig: Immunoglobulin; IL: Interleukin; Jak: Janus kinase; JIA: Juvenile idiopathic arthritis; KLH: Keyhole limpet hemocyanin; MCV: Meningococcal conjugate vaccine; MMF: Mycophenolate; MMR: Measles/mumps/rubella; MTX: Methotrexate; PCV: Pneumococcal conjugate vaccine; PPSV: Pneumococcal polysaccharide vaccine; RA: Rheumatoid arthritis; RTX: Rituximab; SLE: Systemic lupus erythematosus; SSZ: Sulfasalazine; TCZ: Tocilizumab; TNF: Tumor necrosis factor; TT: Tetanus toxoid; UST: Ustekinumab.
} 


\section{Competing interests}

ZHM has no competing interests to declare. COB has served as a consultant and investigator for Genentech/Roche for vaccine studies, and as a consultant to Bristol-Myers-Squibb, Pfizer, Eli Lilly, and Merck-Serrono regarding vaccines.

\section{Acknowledgements}

We would like to thank the Rheumatology Research Foundation Scientist Development Award for their support of ZHM and of this work

\section{Published online: 23 December 2014}

\section{References}

1. Curtis JR, Arora T, Narongroeknawin P, Taylor A, Bingham CO 3rd, Cush J, Saag KG, Safford M, Delzell E: The delivery of evidence-based preventive care for older Americans with arthritis. Arthritis Res Ther 2010, 12:R144.

2. Duchet-Niedziolka P, Launay O, Coutsinos Z, Ajana F, Arlet P, Barrou B, Beytout J, Bouchaud O, Brouqui P, Buzyn A, Chidiac C, Couderc LJ, Debord T, Dellamonica P, Dhote R, Duboust A, Durrbach A, Fain O, Fior R, Godeau B, Goujard C, Hachulla E, Marchou B, Mariette X, May T, Meyer O, Milpied N, Morlat $\mathrm{P}$, Pouchot J, Tattevin $\mathrm{P}$, et al: Vaccination in adults with autoimmune disease and/or drug related immune deficiency: results of the GEVACCIM Delphi survey. Vaccine 2009, 27:1523-1529.

3. Patel NC, Hertel PM, Estes MK, de la Morena M, Petru AM, Noroski LM, Revell PA, Hanson IC, Paul ME, Rosenblatt HM, Abramson SL: Vaccineacquired rotavirus in infants with severe combined immunodeficiency. N Engl J Med 2010, 362:314-319.

4. Harpaz R, Ortega-Sanchez IR, Seward JF, Advisory Committee on Immunization Practices (ACIP) Centers for Disease Control and Prevention (CDC): Prevention of herpes zoster: recommendations of the Advisory Committee on Immunization Practices (ACIP). MMWR Recomm Rep 2008, 57:1-30. quiz CE2-4.

5. Zhang J, Xie F, Delzell E, Chen L, Winthrop KL, Lewis JD, Saag KG, Baddley JW, Curtis JR: Association between vaccination for herpes zoster and risk of herpes zoster infection among older patients with selected immunemediated diseases. JAMA 2012, 308:43-49.

6. Winthrop KL, Baddley JW, Chen L, Liu L, Grijalva CG, Delzell E, Beukelman T, Patkar NM, Xie F, Saag KG, Herrinton U, Solomon DH, Lewis JD, Curtis JR: Association between the initiation of anti-tumor necrosis factor therapy and the risk of herpes zoster. JAMA 2013, 309:887-895.

7. Pileggi GS, de Souza CB, Ferriani VP: Safety and immunogenicity of varicella vaccine in patients with juvenile rheumatic diseases receiving methotrexate and corticosteroids. Arthritis Care Res (Hoboken) 2010, 62:1034-1039.

8. Borte $\mathrm{S}$, Liebert UG, Borte M, Sack U: Efficacy of measles, mumps and rubella revaccination in children with juvenile idiopathic arthritis treated with methotrexate and etanercept. Rheumatology (Oxford) 2009, 48:144-148.

9. Scheinberg M, Guedes-Barbosa LS, Mangueira C, Rosseto EA, Mota L, Oliveira AC, Lima RA: Yellow fever revaccination during infliximab therapy. Arthritis Care Res (Hoboken) 2010, 62:896-898.

10. Shearer WT, Fleisher TA, Buckley RH, Ballas Z, Ballow M, Blaese RM, Bonilla FA, Conley ME, Cunningham-Rundles C, Filipovich AH, Fuleihan R, Gelfand EW, Hernandez-Trujillo V, Holland SM, Hong R, Lederman HM, Malech HL, Miles S, Notarangelo LD, Ochs HD, Orange JS, Puck JM, Routes JM, Stiehm ER, Sullivan K, Torgerson T, Winkelstein J, Medical Advisory Committee of the Immune Deficiency Foundation: Recommendations for live viral and bacterial vaccines in immunodeficient patients and their close contacts. J Allergy Clin Immunol 2014, 133:961-966.

11. Carr S, Allison KJ, Van De Velde LA, Zhang K, English EY, Iverson A, Daw NC, Howard SC, Navid F, Rodriguez-Galindo C, Yang J, Adderson EE, McCullers JA, Flynn PM: Safety and immunogenicity of live attenuated and inactivated influenza vaccines in children with cancer. $J$ Infect Dis 2011, 204:1475-1482.

12. Bridges CB, Woods L, Coyne-Beasley T, ACIP Adult Immunization Work Group, Centers for Disease Control and Prevention (CDC): Advisory Committee on Immunization Practices (ACIP) recommended immunization schedule for adults aged 19 years and older - United States, 2013. MMWR Surveill Summ 2013, 62:9-19.

13. Jackson LA, Gurtman A, van Cleeff M, Frenck RW, Treanor J, Jansen KU, Scott DA, Emini EA, Gruber WC, Schmoele-Thoma B: Influence of initial vaccination with 13-valent pneumococcal conjugate vaccine or 23-valent pneumococcal polysaccharide vaccine on anti-pneumococcal responses following subsequent pneumococcal vaccination in adults 50 years and older. Vaccine 2013, 31:3594-3602.

14. Elkayam O, Paran D, Caspi D, Litinsky I, Yaron M, Charboneau D, Rubins JB: Immunogenicity and safety of pneumococcal vaccination in patients with rheumatoid arthritis or systemic lupus erythematosus. Clin Infect Dis 2002, 34:147-153.

15. Dixon WG, Abrahamowicz M, Beauchamp ME, Ray DW, Bernatsky S, Suissa S, Sylvestre MP: Immediate and delayed impact of oral glucocorticoid therapy on risk of serious infection in older patients with rheumatoid arthritis: a nested case-control analysis. Ann Rheum Dis 2012, 71:1128-1133.

16. Greenberg JD, Reed G, Kremer JM, Tindall E, Kavanaugh A, Zheng C, Bishai W, Hochberg MC, CORRONA Investigators: Association of methotrexate and tumour necrosis factor antagonists with risk of infectious outcomes including opportunistic infections in the CORRONA registry. Ann Rheum Dis 2010, 69:380-386.

17. Kapetanovic MC, Saxne T, Nilsson JA, Geborek P: Influenza vaccination as model for testing immune modulation induced by anti-TNF and methotrexate therapy in rheumatoid arthritis patients. Rheumatology (Oxford) 2007, 46:608-611.

18. Bingham CO 3rd, Looney RJ, Deodhar A, Halsey N, Greenwald M, Codding C, Trzaskoma B, Martin F, Agarwal S, Kelman A: Immunization responses in rheumatoid arthritis patients treated with rituximab: results from a controlled clinical trial. Arthritis Rheum 2010, 62:64-74.

19. van Assen S, Holvast A, Benne CA, Posthumus MD, van Leeuwen MA, Voskuyl AE, Blom M, Risselada AP, de Haan A, Westra J, Kallenberg CG, Bijl $M$ : Humoral responses after influenza vaccination are severely reduced in patients with rheumatoid arthritis treated with rituximab. Arthritis Rheum 2010, 62:75-81.

20. Kapetanovic MC, Roseman C, Jonsson G, Truedsson L: Heptavalent pneumococcal conjugate vaccine elicits similar antibody response as standard 23-valent polysaccharide vaccine in adult patients with RA treated with immunomodulating drugs. Clin Rheumatol 2011, 30:1555-1561.

21. Kapetanovic MC, Roseman C, Jonsson G, Truedsson L, Saxne T, Geborek P: Antibody response is reduced following vaccination with 7-valent conjugate pneumococcal vaccine in adult methotrexate-treated patients with established arthritis, but not those treated with tumor necrosis factor inhibitors. Arthritis Rheum 2011, 63:3723-3732.

22. Bingham CO 3rd, Rizzo W, Kivitz A, Hassanali A, Upmanyu R, Klearman M: Humoral immune response to vaccines in patients with rheumatoid arthritis treated with tocilizumab: results of a randomised controlled trial (VISARA). Ann Rheum Dis 2014. doi: 10.1136/annrheumdis-2013-204427. [Epub ahead of print]

23. Heijstek MW, Kamphuis S, Armbrust W, Swart J, Gorter S, de Vries LD, Smits GP, van Gageldonk PG, Berbers GA, Wulffraat NM: Effects of the live attenuated measles-mumps-rubella booster vaccination on disease activity in patients with juvenile idiopathic arthritis: a randomized trial. JAMA 2013, 309:2449-2456

24. Kollaritsch H, Que JU, Kunz C, Wiedermann G, Herzog C, Cryz SJ Jr: Safety and immunogenicity of live oral cholera and typhoid vaccines administered alone or in combination with antimalarial drugs, oral polio vaccine, or yellow fever vaccine. J Infect Dis 1997, 175:871-875.

25. Gabay C, Bel M, Combescure C, Ribi C, Meier S, Posfay-Barbe K, Grillet S, Seebach JD, Kaiser L, Wunderli W, Guerne PA, Siegrist CA, H1N1 Study Group: Impact of synthetic and biologic disease-modifying antirheumatic drugs on antibody responses to the ASO3-adjuvanted pandemic influenza vaccine: a prospective, open-label, parallel-cohort, singlecenter study. Arthritis Rheum 2011, 63:1486-1496.

26. Mok CC, Ho LY, Fong LS, To CH: Immunogenicity and safety of a quadrivalent human papillomavirus vaccine in patients with systemic lupus erythematosus: a case-control study. Ann Rheum Dis 2013, 72:659-664.

27. Trollmo C, Gudmundsson S, Feltelius N, Rogberg S, Smedegard G, Klareskog $\mathrm{L}$ : Sulphasalazine inhibits human antigen-specific immune responses in vivo. Ann Rheum Dis 2007, 66:481-485.

28. Kanerud L, Engstrom GN, Tarkowski A: Evidence for differential effects of sulphasalazine on systemic and mucosal immunity in rheumatoid arthritis. Ann Rheum Dis 1995, 54:256-262.

29. Zonneveld-Huijssoon E, Ronaghy A, Van Rossum MA, Rijkers GT, van der Klis FR, Sanders EA, Vermeer-De Bondt PE, Hoes AW, van der Net JJ, Engels C, Kuis W, Prakken BJ, Van Tol MJ, Wulffraat NM: Safety and efficacy of 
meningococcal c vaccination in juvenile idiopathic arthritis. Arthritis Rheum 2007, 56:639-646.

30. Ribeiro AC, Guedes LK, Moraes JC, Saad CG, Aikawa NE, Calich AL, Franca IL, Carvalho JF, Sampaio-Barros PD, Goncalves CR, Borba EF, Timenetsky Mdo C, Precioso AR, Duarte A, Bonfa E, Laurindo IM: Reduced seroprotection after pandemic H1N1 influenza adjuvant-free vaccination in patients with rheumatoid arthritis: implications for clinical practice. Ann Rheum Dis 2011, 70:2144-2147.

31. Holvast A, Huckriede A, Wilschut J, Horst G, De Vries JJ, Benne CA, Kallenberg CG, Bijl M: Safety and efficacy of influenza vaccination in systemic lupus erythematosus patients with quiescent disease. Ann Rheum Dis 2006, 65:913-918.

32. Keshtkar-Jahromi M, Argani H, Rahnavardi M, Mirchi E, Atabak S, Tara SA Gachkar L, Noori-Froothghe A, Mokhtari-Azad T: Antibody response to influenza immunization in kidney transplant recipients receiving either azathioprine or mycophenolate: a controlled trial. Am J Nephrol 2008, 28:654-660.

33. Holvast A, Stegeman CA, Benne CA, Huckriede A, Wilschut JC, Palache AM, Kallenberg CG, Bijl M: Wegener's granulomatosis patients show an adequate antibody response to influenza vaccination. Ann Rheum Dis 2009, 68:873-878.

34. Sanchez-Fructuoso Al, Prats D, Naranjo P, Fernandez-Perez C, Gonzalez MJ, Mariano A, Gonzalez J, Figueredo MA, Martin JM, Paniagua V, Fereres J, Gomez de la Concha E, Barrientos A: Influenza virus immunization effectivity in kidney transplant patients subjected to two different triple-drug therapy immunosuppression protocols: mycophenolate versus azathioprine. Transplantation 2000, 69:436-439.

35. Struijk GH, Minnee RC, Koch SD, Zwinderman AH, van Donselaar-van der Pant KA, Idu MM, ten Berge IJ, Bemelman FJ: Maintenance immunosuppressive therapy with everolimus preserves humoral immune responses. Kidney Int 2010, 78:934-940.

36. Mercado U, Acosta H, Diaz-Molina R: Antibody response to pneumococcal polysaccharide vaccine in systemic sclerosis. J Rheumatol 2009, 36:1549-1550

37. Palestine AG, Roberge F, Charous BL, Lane HC, Fauci AS, Nussenblatt RB: The effect of cyclosporine on immunization with tetanus and keyhole limpet hemocyanin (KLH) in humans. J Clin Immunol 1985, 5:115-121.

38. Versluis DJ, Beyer WE, Masurel N, Wenting GJ, Weimar W: Impairment of the immune response to influenza vaccination in renal transplant recipients by cyclosporine, but not azathioprine. Transplantation 1986, 42:376-379.

39. Kapetanovic MC, Saxne T, Sjoholm A, Truedsson L, Jonsson G, Geborek P. Influence of methotrexate, TNF blockers and prednisolone on antibody responses to pneumococcal polysaccharide vaccine in patients with rheumatoid arthritis. Rheumatology (Oxford) 2006, 45:106-111.

40. Ferreira I, Isenberg D: Vaccines and biologics. Ann Rheum Dis 2014, 73:1446-1454

41. Hua C, Barnetche T, Combe B, Morel J: Effect of methotrexate, anti-tumor necrosis factor alpha, and rituximab on the immune response to influenza and pneumococcal vaccines in patients with rheumatoid arthritis: a systematic review and meta-analysis. Arthritis Care Res (Hoboken) 2014, 66:1016-1026.

42. Kapetanovic MC, Kristensen LE, Saxne T, Aktas T, Morner A, Geborek P. Impact of anti-rheumatic treatment on immunogenicity of pandemic H1N1 influenza vaccine in patients with arthritis. Arthritis Res Ther 2014, 16:R2.

43. Moreland LW, Bucy RP, Weinblatt ME, Mohler KM, Spencer-Green GT, Chatham WW: Immune function in patients with rheumatoid arthritis treated with etanercept. Clin Immunol 2002, 103:13-21.

44. Tay L, Leon F, Vratsanos G, Raymond R, Corbo M: Vaccination response to tetanus toxoid and 23-valent pneumococcal vaccines following administration of a single dose of abatacept: a randomized, open-label, parallel group study in healthy subjects. Arthritis Res Ther 2007, 9:R38

45. Schiff M, Kaell A, Tay L, Vratsanos G, Baart K: Pneumococcal vaccine in rheumatoid arthritis patients with an inadequate response to anti-TNF Therapy treated with abatacept in the ARRIVE Trial. Ann Rheum Dis 2007, $66: 437$.

46. Abrams JR, Lebwohl MG, Guzzo CA, Jegasothy BV, Goldfarb MT, Goffe BS, Menter A, Lowe NJ, Krueger G, Brown MJ, Weiner RS, Birkhofer MJ, Warner GL, Berry KK, Linsley PS, Krueger JG, Ochs HD, Kelley SL, Kang S: CTLA4lg-mediated blockade of T-cell costimulation in patients with psoriasis vulgaris. J Clin Invest 1999, 103:1243-1252.
47. Alten R, Bingham CO, Cohen S, Calabrese L, Curtis JR, Blick A, Fay J, Kelly S, Luo A, Wong D, Genovese MA: Antibody response to pneumococcal and influenza vaccineation in patients with RA receiving subcutaneous abatacept. Ann Rheum Dis 2013, 72:579. Abstract SAT0001.

48. Oren S, Mandelboim M, Braun-Moscovici Y, Paran D, Ablin J, Litinsky I, Comaneshter D, Levartovsky D, Mendelson E, Azar R, Wigler I, Balbir-Gurman A, Caspi D, Elkayam O: Vaccination against influenza in patients with rheumatoid arthritis: the effect of rituximab on the humoral response. Ann Rheum Dis 2008, 67:937-941.

49. Arad U, Tzadok S, Amir S, Mandelboim M, Mendelson E, Wigler I, SarbagilMaman H, Paran D, Caspi D, Elkayam O: The cellular immune response to influenza vaccination is preserved in rheumatoid arthritis patients treated with rituximab. Vaccine 2011, 29:1643-1648.

50. Chatham WW, Wallace DJ, StohI W, Latinis KM, Manzi S, McCune WJ, Tegzova D, McKay JD, Avila-Armengol HE, Utset TO, Zhong ZJ, Hough DR, Freimuth WW, Migone TS, BLISS-76 Study Group: Effect of belimumab on vaccine antigen antibodies to influenza, pneumococcal, and tetanus vaccines in patients with systemic lupus erythematosus in the BLISS-76 trial. J Rheumatol 2012, 39:1632-1640

51. Mori S, Ueki Y, Hirakata N, Oribe M, Hidaka T, Oishi K: Impact of tocilizumab therapy on antibody response to influenza vaccine in patients with rheumatoid arthritis. Ann Rheum Dis 2012, 71:2006-2010.

52. Bingham CO 3rd, Rizzo W, Kivitz A, Hassanali A, Upmanyu R, Klearman M: Humoral immune response to vaccines in patients with rheumatoid arthritis treated with tocilizumab: results of a randomised controlled trial (VISARA). Ann Rheum Dis 2014. doi: 10.1136/annrheumdis-2013-204427.

53. Brodmerkel C, Wadman E, Langley RG, Papp KA, Bourcier M, Poulin Y, Ho V, Guenther L, Kunynetz R, Nigen S, Vender R, Wasel N, Hsu MC, Szapary P: Immune response to pneumococcus and tetanus toxoid in patients with moderate-to-severe psoriasis following long-term ustekinumab use. $J$ Drugs Dermatol 2013, 12:1122-1129.

54. Winthrop K, Racewicz A, Lee E, Wilkinson B, Zwillich S, Soma K, Rottinghaus S, Kawabata T, Riese R, Wood S, Bradley J, Bingham CO 3rd: Evaluation of influenza and pneumococcal vaccine responses in patients with rheumatoid arthritis receiving tofacitinib. Arthritis Rheum 2013, 65:Abstract 1284.

55. van Assen S, Agmon-Levin N, Elkayam O, Cervera R, Doran MF, Dougados M, Emery P, Geborek P, loannidis JP, Jayne DR, Kallenberg CG, Muller-Ladner U, Shoenfeld Y, Stojanovich L, Valesini G, Wulffraat NM, Bijl M: EULAR recommendations for vaccination in adult patients with autoimmune inflammatory rheumatic diseases. Ann Rheum Dis 2011, 70:414-422.

\section{doi:10.1186/s13075-014-0506-0}

Cite this article as: McMahan and Bingham III: Effects of biological and non-biological immunomodulatory therapies on the immunogenicity of vaccines in patients with rheumatic diseases. Arthritis Research \& Therapy 2014 16:506. 